\title{
SOCIAL CHANGES AND LEVELS OF ONTOLOGICAL INSECURITY OR SENSES OF RISKS
}

\author{
Baris Cagirkan \\ Research Assistant, Bitlis Eren University,Turkey, bcagirkan@gmail.com
}

\begin{abstract}
Historically, risks are the part of people's life; however, the levels and the threats of risks have been changed through the history. Technological improvements and globalisation make more simplistic and easier human's everyday life in some ways, but they have such a remarkable effect on the levels of ontological insecurity and senses of risks. The risks and ontological insecurity have been changed throughout the history. In premodern times, risks were natural disasters, wild animals, heavy weather conditions, such as heavy snow and rain. However, people are facing different, more influential, more vital risks due to the technological improvements, communication tools, globalisation, Americanization. These risks, which we are facing today, can be classified into four different primary groups; such as Economic, Societal, Environmental, Technological, Geopolitical risks. In this paper, societal risks are the main discussion subjects.
\end{abstract}

Keywords: Social changes, risk society, ontological insecurity, second modernity.

\section{INTRODUCTION}

In our day-to-day lives, we are sensitive to the cluster of risks that affect our relations with the self, with others, with a state, and with the broader culture (Elliot, 2002). In everyday lay people's language, risk has a broad range of connotations: fear of specific hazards, concern for the interdependency of humans and technological systems, uncertainty regarding financial gain or loss, fear of the malevolent forces of nature, or the thrill of adventure, or worry about the competence and trustworthiness of those who manage risks (Lupton, 1999; Jaeger, Renn, Rosa, and Webler, 2001). People are scared being the victim of crime, falling prey to cancer, being in a car accident, and losing their jobs. It can be claimed that after the Industrial Revelation, societies were changed significantly. Moreover, that era called modern (Ritzer, 1996). Modernity has been defined as the institutions and modes of behaviour established first of all in post-feudal Europe, but it has increasingly become world-historical in their impact in the twentieth century (Giddens, 1991, p. 91). 
Moreover, from Marx through Parsons to Luhmann, modern society is constantly changing, expanding and transforming itself (Lupton, 1999). These social changes cause sorts of risks, lack of trust and ontological insecurity in contemporary societies. All these are not new things because fears, sense of risk, ontological insecurity have existed all human history (Skey, 2013).

By way of introduction, it is necessary to discuss what risk is and how different it has been used through the history. The notion of risk first appeared in the Middle Ages, related to maritime insurance and used to designate the perils that could compromise a voyage: "At that time, risk identified the possibility of a danger, an act of God, a force majeure, a tempest or other peril of sea that could not be imputed to wrongful conduct. In the modern era, the risk is defined as a systematic way of dealing with hazards and insecurities included and introduced by modernisation itself (Beck, 1992b). Risks are consequences that relate to the threating force of modernisation and its globalisation of doubt. The risk was perceived to be a natural event such as a storm, flood, earthquake, or epidemic rather than a human-made one, which are nuclear radiation, genetically modified foods, or so on. The definition of risk has been changed through the history. The reason for this change comes from the understanding of the world and society. The social changes in society have been defined the notion of risk. The following view gives us another explanation. According to Golding (1992), "changes in the meanings and use of risk are associated with the emergence of modernity, beginning in the seventeenth century and gathering force in the eighteenth century. Risk has become a mechanism for understanding and organising social processes and experiences" (p. 87). The concept of risk, therefore, excluded the idea of human fault and responsibility because modernity changed the people's understanding of risk.

The aim of this paper is to discuss social changes and their effects on ontological insecurity or sense of risk in the modern era. First of all, it will be discussed that what is a risk and how different sociology focuses on risks. After that, trust and ontological security are going to be argued in the case of being features of modern life. Last of all, the concept of world risk society will be criticised. Beck and Giddens' writings are to be primary references for this discussion. The key point of this essay is that social changes have an impact globally today.

\section{THE NOTION OF RISK}

In pre-modern times, the symbolic basis of our uncertainties is anxiety created by disorder, the loss of control over our bodies, our relationships with others, our livelihoods. As in pre-modern times, people may acknowledge that threats exist, but they like to think that something can be done to deal with them; for instance, if they sacrifice something to God, they are in safe (Lupton, 1999). In modernity, risk, in its purely technical meaning, came to rely on conditions in which the probability estimates of an event are able to be known or knowable. In contrast, uncertainty was used as an alternative term when these chances are unpredictable or unknown (Lupton, 1999). To summarise, in modern time, understanding the concept of risk paradigm has been changed.

In terms of comparing risks in pre-modern times with current ones that there are three key differences: (1) in the pre-modern societies, most risks were local in impact, while today many risks are eco-systemic risks; (2) in the past, most risks were geographically limited, while many risks are global in the contemporary societies; and (3) in the past, many risks were likely considered as a group's unique circumstances, while today there is growing public awareness of common risks around globe (Jaeger, Ren, Rosa, and Webber, 2001). Moreover, it is generally identified three generic areas of concern with risk or risk selection; these are: (1) socio-politic risk: dangers to social structure, coming from internal deviants, especially risk from human violence: from crime or external military foes, such as new mass destruction weapons, nuclear weapons; (2) economic risks: threats to the economy, or risks of economic failure, such as global financial crises in 2008, first it begun in America but spread around the world. Many people lost their jobs, and this situation has an impact on the suicide rate in many countries; (3) natural risks: ecological threats to nature and the body; that is, risks from natural world such as an earthquake, tsunami, flood, and so on (Lash et all 2000, p. 57). It can be concluded that human race has been trying to solve its risks problem, but these solutions have brought new risks which are more violent and deadly in human life. 


\section{SECOND OR HIGH MODERNITY AND RISK SOCIETY}

The understanding of the world and society has been changed after the modernity and Enlightenment. Lupton (1999) argues that modernity depends on the notion that "the key to human progress and social order is objective knowledge of the world through scientific exploration and rational thinking" that emerged in the seventeenth century Enlightenment. These two big milestones, modernity, and Enlightenment, have created new paradigms compare to the previous era. One of the most significant paradigms is that the social and natural worlds follow laws that may be measured, calculated and therefore predicted (Lupton, 1999). The radicalization of modernity produces this fundamental irony of risk: science, the state, and the military are becoming part of the problem that people are supposed to solve. This is what reflexive modernisation means: people are not living in a post-modern world but in a more modern world. It is not the crisis, but the victory of modernity (Beck, 2006, p. 45). Individualisation and reflexive modernisation are discussed in Beck and Giddens writings. Because of globalisation, "people feel more interconnected with the world and more vulnerable to global forces increasingly perceived as beyond their control. Individualisation is simultaneously increasing personal choice and autonomy while at the same time contributing to new levels of insecurity and anxiety" (Macnaghten, 2006, p. 67).

In theoretical terms, risk has conventionally been approached as an objective existence to be mastered by calculation and probability. There is a strong coloration between growing public concerns about limitless technoscientific development and the lack of expert control system in managing hazards. Because of this situation, risk has gathered momentum within social sciences (Mythen and Walklate, 2006). According to Beck (1999), high modernity is a word "introduces global risk parameters that previous generations have not had to face. Precisely because of the failure of modern social institutions to control the risks they have created, such as the ecological crisis, risk rebounds as a mostly defensive attempt to avoid new problems and dangers".

The main argument of risk society (Beck, 1986) is the particular quality of new hazards. They occur as side effects of the modern industrial times and are responsible for the self-transformation of modern times (Zinn, 2007). Beck coined risk society in 1986; the intervening years have provided enough reminders of the centrality of risk in contemporary societies. Beck (2002) stated that "the risk society is defined by risks, that are mostly related to human-made hazards and whose consequences are hard to assess" (pp. 40). There has been a spectacular accident, Chernobyl and Fukushima being the most dramatic. AIDS has initiated intense discussion of risk and personal sexual expression. Anxiety about deforestation due to acid rain or economic exploitation, and other slow burning issues have become a permanent background, sometimes through nothing more extraordinary that the arrival of summer (global warming) (Scott, 2000). The theory of world risk society states that modern societies (high modern or second modern) are shaped by new kinds of risks compare to the previous era. Beck (2006) states "such perceptions of global risk are characterized by three features: (1) De-localization: its causes and consequences are not limited to one geographical location or space; they are in principle omnipresent; (2) Incalculableness: its implications are in principle incalculable; at bottom it is a matter of 'hypothetical' risks, which, not least, are based on science- induced not-knowing and normative dissent; (3) Non-compensatibility: the security dream of first modernity was based on the scientific utopia of making the unsafe consequences and dangers of decisions ever more controllable; accidents could occur, as long as and because they were considered compensatible. If the climate has changed irreversibly, if progress in human genetics makes irreversible interventions in human existence possible, if terrorist groups already have weapons of mass destruction available to them, then it is too late" (Beck, 2006, pp. 333-334).

Both Giddens and Beck represent sociological risk society theorists. The sociologists adopting the risk society perspectives are predominantly interested in the macro-social processes; they see as characteristic of late modern societies and their relation to concepts of risk (Ritzer, 1996). These processes include reflexive modernisation or the move towards criticism of the outcomes of modernity, and individualisation, or the breaking down of traditional norms and values (Giddens, 1991). In Anthropologist way of risk society concept is that in contemporary societies, they see risks as having become a central cultural and political concept by which individuals, social groups and institutions. They are organised, monitored and regulated 
(Douglas, 1992). The following insights are central to all risk perspectives: risk has become an increasingly pervasive concept of human existence in contemporary societies; risk is a fundamental aspect of human subjectivity; risk is comprehended as something that can be managed through human intervention; risk is associated with notions of choice, responsibility, and blame (Lupton, 1999). While all societies in the history of humanity have been challenged by threats and dangers. In pre-modern times, there were fears of terrible catastrophes affecting the world and destroying humankind. In the present day, such concerns are commonly linked to the perception that humans (rather than gods or fate) have brought these catastrophes upon themselves. As it discussed that the difference in this late modern era, human responsibility is now attached to risk. People are seen to both cause risks and be responsible for their minimisation (Lupton, 2006). Beck (1992a) argues that the rise of risk society is bound up with the new electronic global economy - a world in which we live on the edge of high technological innovation and scientific improvement, but where no one fully understands the possible global risks and dangers we face today. Furthermore, the level of vulnerability is less than pre-modern times due to globalisation and technology, people and countries are more connected to each other. For instance, when the Fukushima reactor disaster was happened in March 2011, many people feared that nuclear contamination could affect Tokyo, the heart of the nation's business and one of the most crowded city in the world. The risk of a nuclear containment stimulated the awareness of large-scale risks by technology (Baran, 2013). On the basis of Foucault's writings, in modern societies, citizens are not often explicitly regulated by oppressive strategies. They are manipulated to adopt certain practices voluntarily, as being good citizens and never give up to be their interests (Lupton, 2006). The threats are part of the dark side of modernity. At the end of the twentieth century, the use of the risk has not got much to do with probability calculations now. The original connection is only indicated by arm waving in the direction of possible science: the word risk now means danger now, and high risk means much danger (Beck, 1996a; Giddens, 1991).

Fukuyama (1995) states that trust as the belief that arises within a community of regular, honest, and cooperative behaviour, based on commonly shared norms, on the part of other members of the community. People want to trust technology; a plane is not going to break during the flight or seatbelt can protect them if they have a car accident. People trust companies, scientists or technology today. Social theories tend to conceive of trust by pointing to the range of benefits that trust provides. For instance, it is seen as essential for stable relationships, vital for the maintenance of cooperation, fundamental for any exchange and necessary for even the most routine of everyday interactions. In a nutshell, people trust many things in their daily life. We are sure that nothing is going to happen when we cross the street during the green traffic light. However, it is still risky for us because the driver might be drunk or distracted by something else. Trust is discussed in Giddens' book, he argues that trust is one of the features of second modernity; people trust that none of the leaders are going to use a nuclear weapon to destroy the world, but there is a probability to use a nuclear weapon and destroy the world (Giddens, 1990). If the states who have a nuclear weapon decided to use a nuclear weapon, the human race would face the risk altogether. It does not matter who you are, what colour your skin is, what religion you are believing or what is your gender. Humankind would be the same levels of risk to die. Development (OECD) estimates "4 billion people could be living in water- scarce areas by 2050. According to the World Water Council, $80 \%$ to $90 \%$ of the scarce water in many of the world's arid and semi-arid river basins is already being used, and over $70 \%$ of the world's major rivers, no longer reach the sea" (World Economic Forum World Risk Report, 2016). Almost three-fourths of the world's population will sacrifice drinkable water by 2050 . This data shows that how risks have vital impacts on the human's life. Social changes in the modern era have altered many things. Moreover, they caused lack of trust and sense of risk in individual level. According to Giddens, ontological security is brought about when humans are able to trust that they can bracket off all sorts of possibilities; that they can, therefore, rely on a social normality, a predictability, which then structures their practical everyday interactions as natural, healthy, and imbued with common sense (Croft, 2012). Ontological Security points to "the confidence that most human beings have in the continuity of their self-identity and the constancy of the surrounding social and material environments of action" (Giddens, 1991, pp. 92).

Regarding social changes and their impacts, social changes have an effect globally in the contemporary era. One of the main reasons is for that as McLuhan (1964) described the world as "a global village". In the 
village, small changes can have an effect on the individual level and community level. Using global village metaphor, the fall of the global capitalist economy affects the life changes tens of millions of people today, a malfunction in a nuclear power plant equally may kill or harm millions of people. Giddens (1990) refers to the double-edged character of modernity or the risks associated with the drive for progress. Because of disembedding mechanisms and globalisation, events now may have potentially disastrous effects that are far more wide reaching than pre-modern times. Giddens (1990) describes late modernity, therefore, as a "risk culture" (1991, pp. 3). As an outcome of modernity, there is far greater uncertainty ever previously existed today. Everything is flowing and changing faster and faster; such as a new kind of capitalism, a new form of economy, a new kind of global order, a new kind of society and a new kind of personal life are coming into being (Beck, 1999). All of them differ from earlier phases of social developments. Giddens identifies modern institutions as being central to the nature of modernity. As long as the institutions of modernity endure, people are never able to control entirely either the path or the pace of this journey. Giddens calls this effect of modernity as a juggernaut. In turn, people might not be able to feel completely secure, because the terrain across which it runs is fraught with risks of high consequence (Giddens, 1990).

Social stability is under risk according to Global Risk Report 2016, and it has been challenged by various and profound transformations that impact many countries worldwide range. These changes result from highspeed technological progress, globalisation, wealth and income concentration, shifting demographics, lack of job opportunities and a changing climate. Social changes cause raising the level of risk in people's daily life. Calculation and predictability are two main features of contemporary society. People are living in risk society that means some expert can calculate the impact of risks. This calculation brings to question that how we can cover the risks damage. When people begin to work in companies or factories, their businesses or factories provide health insurance against industrial accidents which might happen. As Beck (1992a) argues "the changing nature of risk in an age of globalisation fractures the calculating of risks for purposes of insurance. Individually and collectively, people do not fully know or understand many of the risks, which people currently face today; people can only attempt to calculate them accurately regarding probability, compensation, and accountability". Living in a risk society means living with a calculative attitude to the open possibilities of action, positive and negative, with which, as individuals and globally, we are confronted in a continuous way in our contemporary social existence (Giddens, 1991).

Discussing the level of risks' effects that risks have become a major force of political mobilisation, often replacing references to, for example, inequalities associated with class, race, and gender. All those risks have impacts on a global, local and personal level. Because of globalisation, the force of labour is also global today. New international division of labour creates the globalised interdependencies of production, consumption, and geopolitical arrangement, which mean that people everywhere are coming to share a common set of risks. No one could escape a nuclear holocaust, ozone depletion, Green House Effect, Climate change (Jaeger, Renn, Rosa, and Webler, 2001). The table chart shows the Top 5 Global Risks regarding Impact. It can be concluded that societal risks are getting more significant last two years. For example, economic risks were more important than others between 2010 and 2014. Economic problem was chosen as a first risk compared to others but in 2016, the understanding of risks has been changed, and environmental issue is chosen the most significant risk among others.

Top 5 Global Risks in Terms of Impact

\begin{tabular}{|c|c|c|c|c|c|c|}
\hline 2010 & 2011 & 2012 & 2013 & 2014 & 2015 & 2016 \\
\hline & $\begin{array}{c}\text { Asset price } \\
\text { collapse }\end{array}$ & Fiscal crises & Major systemic & Major systemic & Fiscal crises & Water crises $\begin{array}{c}\text { Failure of } \\
\text { climate- } \\
\text { change } \\
\text { mitigation }\end{array}$ \\
\hline
\end{tabular}


IJASOS- International E-Journal of Advances in Social Sciences, Vol. II, Issue 5, August 2016

2

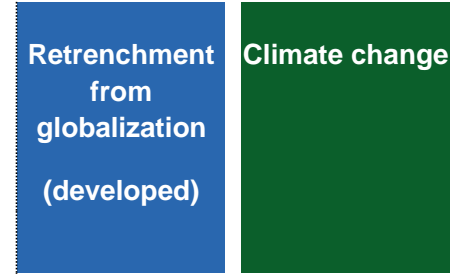

3
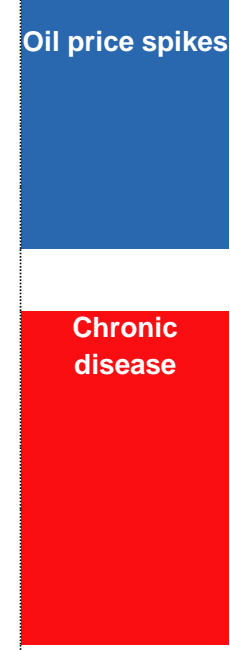

5

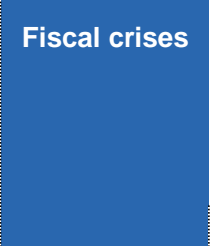

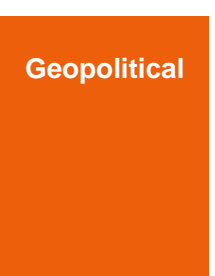
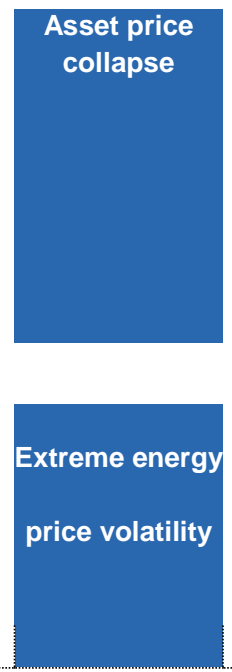
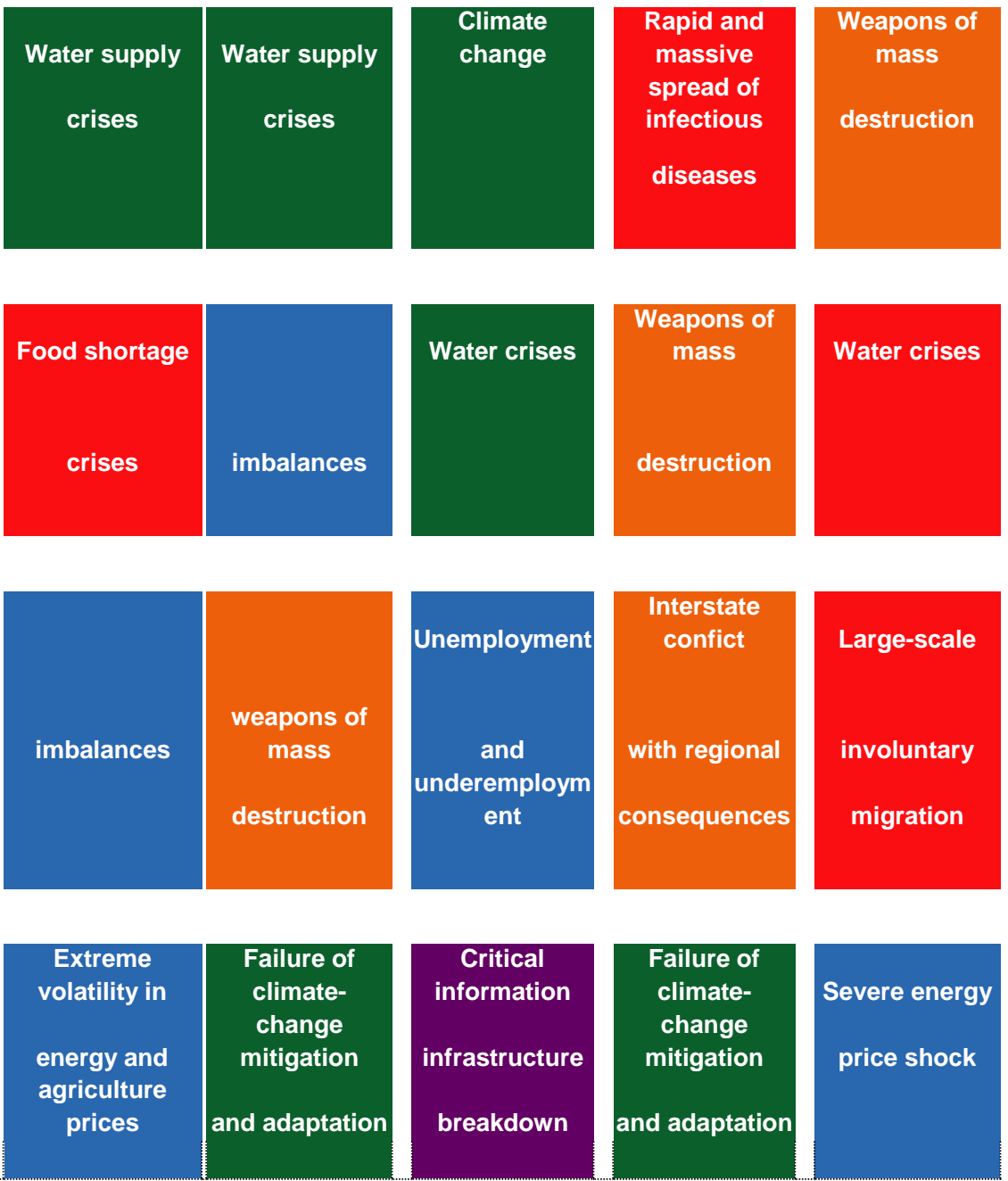

Economic Environmental Geopolitical Societal Technological

Source: World Economic Forum 20010-2016, Global Risks Reports 2016.

There are so many globally significant crises have been in the headline recent years, and they are various from the refugee crisis to economic slowdowns in emerging markets, from the numbers of terrorist attacks (Charlie Hebdo attack to Ankara attack), from the COP21 meeting on reducing greenhouse gas emission or the European Union summits to address the Syrian refugee crisis in Europe, global risks have been a remarkable for all countries in the world (World Economic Forum World Risk Report, 2016). Recent studies show that global refugee flows have reached a level that is unprecedented in human history. According to World Risk Report 2016, 59.5 million people were forcibly displaced in the world in 2014. More than half of these recent refugees come from three conflict-ridden countries: Syria, Afghanistan and Somalia. The trend is increasing: during 2014, the number of people displaced was four times higher than in $2010(42,500$ people per day in 2014 and 10,000 people per day in 2010). However, arguing the world risk society, nonWestern cultures share with the West not only the same space and time but also the same basic challenges of the second modernity. The global risk does not mean a global equality of risk (Beck, 1999). Some countries suffer from risks worse than others, for instance, China has worse pollution problems compare with the European Countries. In African territory, starvation is one of the biggest problem and risks for the people, but it is not as significant as in America. In America, obesity is the more problematic than starvation compared to African countries.

\section{CONCLUSION}

Risks have been existed in human history all time. However, the concept of risks and their impacts have been changed through the time. Social changes have effects on the human life in numerous ways. For 
instance, thanks to technology and science, people can protect themselves against some natural disasters, illnesses, or wild animals. This is the bright side of the advanced technology and science. On the other hand, automobile or plane crashes, toxic chemical spills and explosions, nuclear accidents (Fukushima and Chernobyl), food contamination, genetic manipulation, the spread of AIDS, global climate change, ozone depletion, species extinction, and the persistence of nuclear weapons arsenals: the list goes on. Giddens (1991, pp. 10) argues "in the present century thus far, over 100 million people have been killed in wars, a higher proportion of the world's population than in the nineteenth century, even allowing for overall population increase. It can be said that the world in which we live today is a fraught and dangerous one". Nowadays, the world is facing terrorist's attacks everywhere, for example, Brussel and Paris attacks. Thanks to the communication tools and social media, people can communicate each other globally, but terrorist organisations and groups can use social media to make propaganda or organise attacks.

If we compare the risks and ontological insecurity today with past, people face more vital risks in contemporary society. It is possible to infer that people live in an age of risk today that is global, individualistic. Globally; there are so many different risks which people have to face today. These risks can be considered five different group: economic, environmental, societal, geopolitical and technological. As it disused before, societal risks are getting more important in people's life. Individually, people are facing so many risks in their daily lives; for instance, car accident, cyber-bullying, the safety of personal information, credit card or ID card fraud, genetically modified foods, and so on. Risks are so many in our daily life, and people are increasingly aware that no one is entirely safe from the hazards of modern living (Jaeger, Renn, Rosa, and Webler, 2001). The notion of risk is becoming increasingly central to our global society because in the event of the worst possible disaster or accident, the effects of which are long lasting, irreparable and incalculable, there is no institution, which could prevent it or compensate for its effects (Lupton, 1999). On the basis of high or second modernity, calculation and predictability are main features. Calculability provides to predict risks damage in our daily life. That only helps people to predict or calculate the cost of risks which we have to face in our daily lives. There are some organisations and companies to provide insurance and compensation for the risks that we are facing today. In pre-modern times, there was not any flight insurance for passenger or insurance for our house in case of any natural disaster. People can have insurance for their possessions, for instance, mobile phone, automobile, and so on.

\section{REFENCE LIST}

Baran, C. (2013) Paper 8th Pan-European Conference in Warsaw.

Beck, U. (1992a). From Industrial Society to Risk Society: Questions of Survival, Social Structure and Ecological Enlightenment, Theory, Culture and Society, vol. 9 (1), pp. 97-123.

Beck, U. (1992b) Risk Society: Towards a New Modernity. London: Sage.

Beck, U. (1994) Ecological Politics in an Age of Risk. Cambridge: Polity Press.

Beck, U. (1996a). World risk society as cosmopolitan society? Ecological questions in a framework of manufactured uncertainties. Theory, Culture and Society, vol. 13 (4), pp. 1-32.

Beck, U. (1999) World Risk Society IN: Lemert, C. (eds.) (2013). Social Theory. Boulder: Westview Press.

Beck, U. (2002) The Terrorist Threat: World Risk Society Revisited. Theory Culture Society, vol. 19 (39), pp. 39-55.

Beck, U. (2006). Living in the world risk society. Economy and Society, vol. 35 (3), pp. 329-345.

Croft, S. (2012). Constructing Ontological Insecurity: The Insecuritization of Britain's Muslims. Contemporary Security Policy, vol. 33(2), pp. 219-235.

Douglas, M. (1992) Risk and Blame: Essays in Cultural Theory. London:

Routledge. 
Elliot, A. (2002). Beck's Sociology of Risk: A Critical Assessment. Sociology, vol. 36 (2), pp. 293-315.

Fukuyama, F. (1995) Trust: Social Virtues and the Creation of Prosperity. New York: Free Press.

Giddens, A. (1990) Post-Modernity or Radicalized Modernity? IN: Lemert, C. (eds.) (2013). Social Theory. Boulder: Westview Press.

Giddens, A. (1991) The Consequences of Modernity. Cambridge: Polity Press.

Golding, D. (1992) A Social and Programmatic History of Risk Research IN: Krimsky, S. and Golding, D. (eds.) Westport: Praeger Publishers.

Jaeger, C. C., Renn, O., Rosa, E. A. and Webler, T. (2001) Risk, Unceratnity, and Rational Action. London: Earthscan Publications.

Lash, S. (2000) Risk Culture IN: Adam, B., Beck, U. and Loon, J. V. (eds.) London: Sage.

Lupton, D. (1999) Risk. London: Routledge.

Lupton, D. (2006) Sociology and Risk IN: Mythen, G. and Walklate, S. (eds.) Beyond the Risk Society. Berkshire: McGrave Hill Education.

Macnahten, P. (2006) Environment and Risk IN: Mythen, G. and Walklate, S. (eds.) Beyond the Risk Society. London: Open University Press.

Mythen, G. and Walklate, S. (eds.) (2006) Beyond the Risk Society. Berkshire: McGrave Hill Education.

Ritzer, G. (eds.) (1996) Modern Sociological Theory, 4nd ed. Singapore: McGraw-Hill.

Scott, A. (2000) Risk Society or Angst Society? Two Views of Risk, Conciousness and Community IN: Adam, B., Beck, U. and Loon, J. V. (eds.) London: Sage.

Skey, M. (2013). What does it mean to be cosmopolitan? An examination of the varying meaningfulness and commensurability of everyday 'cosmopolitan' practices, Identities, vol. 20(3), pp. 235-252.

Zinn, J. (eds.) (2007) Social Theories on Risk and Uncertainty. Oxford: Blackwell. 